\title{
Overcoming the Challenges of Masturbation among Students of Tertiary Institutions in Nigeria through Sex Education and Educational Leadership
}

\author{
Innocent Joshua Chiawa Igbokwe \\ Department of Educational Management and Policy, Nnamdi Azikiwe University, Awka \\ ic.igbokwe@unizik.edu.ng
}

\section{Abstract}

Masturbation is assuming an exponential increase in proportion among students of tertiary institutions in Nigeria. The challenges of masturbation appear to be the most important and commonest sexual threat among students today. Sex education and educational leadership remain veritable interventionist approach to dealing with the challenges of masturbation among students. Unfortunately, sex education in this part of the world is uncoordinated or worse still, neglected while educational leadership seems to be a fantasy that ends in the classroom. This study examines the challenges of masturbation prevalent in tertiary institutions among students and thus, identifies the strategies of social intervention through sex education and educational leadership.
Keywords

masturbation; sex education; educational leadership

\section{Introduction}

Individual and national developments in Nigerian are premised on Education as its summit and source. Education is the instrument "par excellence" for bringing about desired change in the life of people and effect national development. Tertiary education is the highest level of education in Nigeria. It is the type of education people pursue after secondary school. It consists of colleges of education, polytechnics, monotechnics, universities and other related institutions (Federal Republic of Nigeria, 2013). Therefore, students of tertiary institutions in Nigeria are those who are still undergoing some training at this level of education. The first very objective of tertiary education in Nigerian is "to develop and inculcate proper values for the survival of the individual and society," (FRN, 2004:24). This implies that it is a place for development and inculcation of proper values into the life of the students through teaching, research, communication, and dissemination of information. The values must be that which helps to foster and enhance the survival of humanity and society.

Unfortunately, the tertiary institutions in Nigeria seem to pay less attention to this her most important goal. This is evidenced in different kinds of anomalies and negative behaviours found among students of higher education such as substance abuse, cultism, examination malpractices, prostitution, militancy and so on. One of the challenges facing students of tertiary students today in Nigeria is masturbation. The survival of individual and human society is largely the work of proper education and effective educational management in the institutions of higher learning. A well trained and nurtured students is capable of handling some basic life challenges like masturbation. Who is to be blamed for the inability of most of these students to objectively deal with this life challenge? Some educationists and stakeholders without hesitation, according to Chukwunyere, Okafor and 
SIASAT Journal of Social, Cultural and Political Studies, 6 (4) October 2021, 219-228

ISSN: 2721-7469 (Print), 2721-7450 (Online)

Innocent Joshua Chiawa Igbokwe: Overcoming the Challenges of Masturbation among Students of Tertiary Institutions in Nigeria through Sex Education and Educational Leadership

https://siasatjournal.com/index.php/siasat

Godwins (2017), put the blame on school administrators, parents, media, teachers, government and even the students while other simply narrow the blame on the failure of relevant authorities and school administrators to provide value re-orientation among students and of course, effective educational leadership. Hence, this paper tries to reveal how the provision of sex education and educational leadership can assist students overcome the challenges of masturbation.

\section{Review of Literature}

\subsection{The Concept of Masturbation}

Masturbation is a unique sexual habit where one touches or stimulates one's sexual organ for sexual gratification. This may lead to orgasm or not. It is an act of exciting sexual organs by rubbing, stroking, pressing, fondling, or other forms of manipulations (Ibrahim, Ehab, Mahmoud \& Amro, 2017). According to Shekarey, Rostami, Mazdai and Mohammadi (2011), it is totally rejected when one is unmarried and almost considered an unpleasant act in most human societies. It is an act common to both male and female students. It is prevalent today despite the stigma associated with it in several societies.

In USA, for example, each second, more than 0.7 million people masturbate (Wysaski, 2011). It is common among students of tertiary institution in Nigeria. For instance, although masturbation is considered an impious activity in Bangladesh and its practice condemned both from the cultural and the social points view, results of a recent study revealed high prevalence of masturbation among university students (Khan Chowdhurry, Khan Chowdhurry, Nipa, Kabir, Moni \& Kordowicz, 2019). The students masturbate for different reasons. Some engage on it due to ignorance, curiosity, imitation, peer pressure, inferiority complex, premature puberty, fear of Sexual Transmitted Diseases (STDs), family problems, loneliness and so on. The researcher believes that masturbation as the deliberate stimulation of the genital organs in order to derive sexual pleasure is intrinsically evil and students should refrain from the practice. This is informed by the fact that the "Magisterium of the Catholic Church - in the course of a constant tradition - and the moral sense of the faithful have declared without hesitation that masturbation is an intrinsically and seriously disordered act," and "the main reason is that, whatever the motive for acting this way, the deliberate use of the sexual faculty outside normal conjugal relations essentially contradicts the finality of the faculty" (CDF, Persona Humana, 9; CCC, 2352). It is the deliberate use of sexual faculty outside its original, natural, Godgiven intention. It is the use of sexual act outside its purpose. Sexual act is ordered by God to the good of spouses and generation of children.

\subsection{Sex Education}

Sex education is best described as sexuality education. This is to avoid the misunderstanding that it is a way of teaching and encouraging the young ones to have sex. It is learning about the cognitive, emotional, social, interactive and physical aspects of sexuality which should actually begin very early in life and change focus in line with educational and public health priorities of the time (WHO \& BZgA, 2010). Th main aim of sex education is to develop and strengthen the ability of children and young people to make conscious, satisfying, healthy and respectful choices regarding relationships, sexuality and emotional and physical health (UNFPA, 2016). One of the essential parts of the duties of trainers, educational psychologists, policy makers, educational leaders and curriculum planners is sex education and giving it less attention may cause great damages to the structure of the society (Shekarey, Rostami, Mazdai \& Mohammadi, 2011). Sex 
education helps students to achieve healthy sexual behaviour, balanced sex identity, healthy life style

\subsection{Educational Leadership}

One can describe educational leadership as an essential aspect of educational system and processes that determines the direction of policies for any institution. According to Unachukwu (2014), leadership is the ability to focus on moving people forward, the ability to create vision, persuade, guide and direct others toward the realization of this vision. Like management, it is a process, a sequence of coordination of activities in an organization; especially in schools, for the achievement of educational objectives (Shaibu, Odoh \& Odiba, 2017). Leadership is actually the process of using power, authority, influence, vision, persuasion and communication skills to coordinate the behviours of individuals and groups so that their activities and effort are in harmony and produce the desired goal (Chukwu, Nnji \& Bua, 2017; Okon, 2016).

Educational leadership in tertiary institutions is to be seen as the application of management principles and skills for the actualization of educational objectives. It is a display of effective management and "effective management is getting things done in the right way" (Ikwuka, Igbokwe, Adigwe \& Onimisi, 2019). It is the ability and capacity to plan, organize, influence, communicate, and motivate others so as to achieve stipulated educational goals and objectives. This involves the applications of the principles of leading, influencing, controlling, planning, organizing, coordinating, communicating, staffing and so on. For educational leadership to be efficient, effective and successful, the leader must possess, in good measures, qualities of trustworthiness, transparency, integrity, truthfulness, firmness, honesty, discipline, openness, fairness, compassion, flexibility, consistence, decisiveness, creativity, humility, confidentiality, respectfulness and team work. The appropriate education for overcoming challenges of masturbation is sex education directed and monitored by effective and efficient educational leadership.

\section{Results and Discussion}

\subsection{Challenges of Masturbation}

Many students of Nigerian tertiary institutions face the challenges of conflicting, negative, confusing and mythical information about sexuality that are often as a result of inaction and silence of the those entrusted to their care. Some of the challenges of masturbation faced by the students include:

\section{a. Corrosive Misinformation}

A current study reveals that a lot of students in the tertiary institutions get information about masturbation through friends, followed by the internet. In fact, $68.8 \%$ of the students gets their first information about masturbation from their friends and $20.2 \%$ of the students gets it from the internet because significant others are reluctant in addressing sexual health issues (Ibrahim, Ehab, Mahmoud \& Amro, 2017). The common danger with these sources of acquiring knowledge without the guidance of an expert is misinformation. Another harm of this type of learning is inadequate knowledge. Students face the challenges of misinformation when it comes to masturbation. One of such misinformation is the claim of some sex theorists that masturbation could be a tool in reducing unwanted pregnancy and other sexually transmitted infections while empirical evidence indicates that people who report masturbating actually report increased engagement with other sexual activities, including risky, activities, such as having multiple partners (Kaestle \& Allen, 
2011; Gerressu, Mercer, Graham, Wellings, \& Johnson, 2008; Robinson, Bockting, \& Harrell, 2003). The United Nations notices that in many societies, for instance, attitudes and laws discourage public discussion of sexuality and sexual behaviour, and social norms may perpetuate harmful conditions (United Nations Educational, Scientific and Cultural Organization (UNESCO), 2018). Accurate information on masturbation is not easy to get due to the extreme sensitivity of participants to questions on the topic (Kaestle \& Allen, 201). Topics on masturbation seem to be deliberately avoided by parents, lecturers and school authorities in Nigeria.

\section{b. Mythological Presumptions}

One of the challenges of masturbation students face is the existence of myth associated with masturbation. Some students are told a myth that it was unhealthy not to masturbate and that it could be harmful to one's body in the long run if one does not masturbate. This myth is not just untrue but unscientific. Nature has made up provisions to contain natural constant buildup pressure with the human body. According to Evert (2008:127), when one needs "to release seminal fluid, this will come in a natural manner during nocturnal emissions (wet dreams)". Another dangerous myth that creates confusion among students is the claim that masturbation decreases sexual desires. Evert (2008) compares this mythological disinformation like saying that lighter fluid can be used to extinguish a fire because masturbation incites lustful thoughts and teaches a person that he or she deserves and needs sexual gratification whenever the desire arises. Using masturbation as an escape from sex or lust is a dangerous game. It may seem to temporally pacify or appease a person but the person is never satisfied and therefore, will always look for more. Therefore, once sexual orientation can be re-wired, disorganized and distorted by the practice of masturbation. Instead of decreasing the sexual desires, it can actually wake up the untrained sexual beast within. Other myths associated with masturbation that has no scientific evidence is that its practice causes blindness, mental illness, penis shrinkage and so on.

\section{c. Disease Prevention}

The false claim that involvement in masturbation helps one to escape from sexually transmitted diseases (STD) is a big challenge to the students who, sometimes, eventually discover that they have become victims of such diseases. Some studies are quick to emphasis that masturbation is one of the fastest ways of spreading STD in tertiary institutions bec ause students who engage in masturbation live together in hostels or same room and usually share among themselves masturbators or vibrators used for masturbation. Infections spread rapidly in the process. Some studies have equally admitted that masturbation can cause impotence, sex hormones disorders, genital disorders, premature ejaculation, poor vision and general physical body weakness which might lead to the depreciation in the body immunity against diseases (Shekarey, Rostami, Mazdai \& Mohammadi, 2011). The tension of whether masturbation prevent diseases or cause it, is one of the endemic challenges faced by students in the tertiary institutions.

\section{d. Contradictory Studies}

One of the major challenges of students in the tertiary institutions is the influx of contradictory studies rooted in relativized reductionist and subjective experiments. These types of studies that usually contradict one another, create confusion and tension in sexuality of students. The United Nations admitted through its agency that teaching and talking about sexuality can be challenging to the youths in social and contexts where there 
are negative and contradictory messages about sex, gender and sexuality (UNESCO, 2018). For instance, an empirical study conducted by Shekarey, Rostami, Mazdai \& Mohammadi (2011) in Iran showed without any scientific demonstrable evidence that masturbation can lead to impotence, premature ejaculation, genital disorders, sex hormones disorders, poor vision and so on. Another empirical study showed that some perceived masturbation as unhealthy with issues like insomnia, risk of prostate cancer and others (Zimmer \& Imhoff, 2020). Another empirical research gave a report that contradicted the former. Some sexologists have even recommended masturbation as essential for improvement of sexual health (Coleman, 2002). The claim that masturbation brings about reduced sperm quality contributed to the decision of the World Health Organization (2010) to recommend an intermediate duration from 2 to 7 days of sexual abstinence before sperm donation. A recent study is calling for the review of the recommendation on the ground that a new finding shows superior quality sperm within short term abstinence periods (Ayad, van der Horst, and Du Plessis, 2018). Conflicts research findings on masturbation are sources of concerns to student in their quest for exploration.

\subsection{Overcoming the Challenges of Masturbation through Sex Education and Educational Leadership}

Sex education and educational leadership provide a unique role in the preparation of students of tertiary institution for a fulfilling, safe, appropriate, and responsible lifestyle in a world filled with gender-based violence (GBV), sexually transmitted diseases (STDs) and host of others. Students can be assisted to overcome the challenges of masturbation through these ways:

\section{a. Information Filltering and Analyticity}

It has been pointed out that one of the major challenges of masturbation students have is misinformation and contradictory presentations. Using the tools of sex education, educational leaders should provide certified, verified reliable and objective information about the nature and effects of masturbation to the students. They are to be made to understand the distinction between the benefit ascribed to an act and the nature of it. This will help them filter misleading information and make proper analytical distinctions of every information presented to them. Something that appears to have some social, economic or medically benefit may be morally objectionable. The Catholic Church holds for centuries with biblical and scientific evidences that masturbation is intrinsically evil and should not be encouraged irrespective of some benefits alluded to it. Marijuana has some benefits but morally evil for students to indulge in it. Sex has some benefits but is morally offensive when it takes place between unmarried people. Educational leaders must see that it is their responsibility to provide proper sexual information and supportive counseling to motivate healthy and positive sexual attitudes in the students. Information filtering and media literacy should enable the students know that not all pieces of information provided in public platforms are not true.

\section{b. Mind-Body Control}

One area of sex education that educational leadership is to provide for the students is the practice of mind-body control through discipline and self-control. The human mind can be trained and tamed as in the associationist classical conditioning of Pavlov's dog that was conditioned or trained to associate the bell with food such that it would begin salivating at the sound of the bell. In fact, Evert (2008) insists that the pleasure centre of the human brain called Medial Pre-optic Nucleus (MPN) is the most easily trained part of 
the human mind such that when sexual energy or pleasure is released in a person, this part of the brain is rewarded with whatever the person is doing, perceiving, looking at and so on. Studies have equally proven that there is a relationship between what one believes or someone's belief system and abstention from aberrant behaviours (Shekarey, Rostami, Mazdai \& Mohammadi, 2011). Sex education that is professionally and properly executed in the tertiary institutions is capable of empowering the students to re-direct and re-channel their sexual energies responsibly and wisely.

\section{c. Appropriation of Value Education}

The leadership of tertiary institutions can help students overcome the challenges of masturbation by integration of value education and in the training of students. Value education helps the students to know the different between what is wrong and what is right. It helps them to make right choices. It helps them get a clear picture of how to deal with the challenges of masturbation and thus, give prudent behaviourial responses to it. It inculcates worthwhile values into students through education by teaching them the courage to choose what is good over evil (Kalu, Jombo-Umeh \& Amadi, 2017). One of the major ways of instilling social values in the life of the students is through proper and adequate sexuality education. This is because it does not only improve their sexual development but gradually equips and empowers the students with reasonable information, skills, and positive values to understand and enjoy their sexuality, have safe and fulfilling relationships and take responsibility for their own and other people's sexual health and well-being (WHO \& BZgA, 2010). Students should be encouraged to appreciate and appropriate value education.

\section{d. School-Based Publicization Programme}

One way of using sex education and educational leadership for the school authority and stakeholders to make provisions for publicization and sensitization programmes in school that should be based on masturbation challenges. These kinds of programmes will help to remove the secrecy involved with subjects like masturbation in Nigeria. Students are susceptible to dangers when a subject is not publicly discussed. A lot of anti-social remedies and misinformation go on clandestinely. A recent study shows that in some places and cultures in the world, like in the Middle East, masturbation is one of the most sensitive and uncomfortable topics to discuss, a stigmatized sexual behaviour, which is publicly referred to as the secret habit (Ibarhim, Ehab, Mahmoud \& Amro, 2017).

Interestingly, Ibarhim, Ehab, Mahmoud and Amro (2017), noticed that $93.2 \%$ of the students they sampled expressed willingness to know more about masturbation. The introduction of school-based sexuality education programmes is practiced in some civilized countries like Sweden, France, United Kingdom, Portugal, Spain, Estonia, Ukraine and Armenia. A country like Ireland made it mandatory in both primary and secondary schools (UNFPA, 2016). Again, the International technical guidance on sexuality education (the Guidance) emphasizes the need for programmes that are informed by evidence, adapted to the local context, and logically designed to measure and address factors such as beliefs, values, attitudes, and skills which, in turn, may affect health and well-being in relation to sexuality (UNESCO, 2018). Therefore, school-based publicization programmes should be a thorough approach of educating naïve and schooled up students of tertiary institutions on the challenges of masturbation and how to overcome them. 


\section{e. Re-orientation for Social Resistance Skills}

It is already observed that involvement in masturbation and masturbation myths usually have its roots in school through peer pressure and negative modelling. There is also need for the leadership in the tertiary institutions to integrate re-orientation programmes for social resistance skills (like observing of personal boundaries) in the institutional curriculum which will assist the students in resisting peer pressure. It is evident that countries are increasingly acknowledging the importance of equipping young people with the knowledge and skills to make responsible choices in their lives, particularly in a context where they have greater exposure to sexually explicit material through the internet and other media (UNESCO, 2018). That is to say that young people in higher institutions and beyond should be taught on the resistance skills of rejecting anti-social values and accepting social values, and reasons for it. Some authors suggest providing of social resistance skills like calligraphy, swimming, hiking and so on (Shekarey, Rostami, Mazdai \& Mohammadi, 2011). This will help the students to focus not only on how to say "no" but also on what to say "yes" to and thereby make better and wiser safety decisions. They can be taught of people, men and women, who stood up for social values they believed in and resisted what everyone else condoned.

\section{f. Destigmatization of those who Masturbate}

For the fact that the term masturbation is mainly stigmatized word and taboo in some cultures, educational leaders are to make extra efforts to ensure that those who are weakened by the proclivity of masturbation are not victimized and stigmatized. It should rather be seen as human sexual weakness that one can actually overcome. Higgins, Trussell, Moore and Davidson (2010), admitted that there are social stigma, taboos and myths regarding sharing of information about sexual activities all over the world. This stigmatization is popular with masturbation (Aboul-Enein, Bernstein, \& Ross, 2016). The danger of stigmatizing, labelling or tagging students who masturbate is that those who are willing to seek help and counselling to quit masturbation will no longer have the courage to meet sexuality therapists and have meaningful engagement with them. A report suggests that majority of students $(63.2 \%)$ who practice masturbation want to quit and $30.5 \%$ percent of them needs helps to quit (Ibrahim, Ehab, Mahmoud \& Amro, 2017). Stigmatizing students who masturbate will certainly undermine their openness and willingness to receive help.

\section{g. Policy Provision and Implementation}

One of the ways school authorities and educational leaders should help students overcome challenges of masturbation is by providing supportive and all-inclusive institutional laws and policies on positive or holistic sex education in tertiary institutions and pointing out that it is a matter of institutional policy and not about individual preferences. Creating and strengthening policies that support the provision of comprehensive sex education is necessary because of the sensitive, and sometimes controversial nature of the subject (UNESCO, 2018). It is also the duty of the educational leaders to put in place institutional basis for the implementation of sex education programmes; anticipating and addressing the sensitivities concerning the implementation of comprehensive sex education programmes; setting standards on confidentiality; setting standards of appropriate behaviour; protecting and supporting the lecturers whose duties are to teach sex education, and if appropriate, protecting or increasing their status within the school and the community (UNESCO, 2018). This approach will, no doubt, help students combat the challenges of masturbation. 


\section{h. Holistic Pedagogy to Sex Education}

Educational leaders in the tertiary institutions can help the students face the challenges of masturbation by ensuring that there is a shift from the traditional approach of teaching sex education to the improved holistic pedagogy. The traditional approach to sex education is that of fear and negativity. This approach has centred on the potential risks of sexuality such as unintended pregnancy and STD. It is aimed out scaring the students and does not help them to respond to their need for information and skills and, in all too many cases, it simply has no relevance to their lives (WHO \& BZgA, 2010). An illustration will be a study carried out by Shekarey, Rostami, Mazdai and Mohammadi (2011) where sex education is defined as a process of acquiring knowledge and forming awareness, approach and behaviour about gender, sexual identity, sexual awareness, appropriate behaviour and confidence in our relationship with the opposite sex so that we are immune from sexual abuses, inadvertent pregnancy, sexually transmitted diseases like AIDS and so on. This approach to sex education is aimed at avoiding of something.

The objective of traditional understanding of sex education is negative, to avoid pregnancy and diseases when dealing the opposite sex. It is a reductionist understanding of sex education. Sex education must be holistic to achieve positive results. This means that the holistic approach to sex education is what efficient and effective leadership can provide for the students to assist them in overcoming the challenges of masturbation and other sexuality issues. Holistic pedagogy to sex education is the positive sexuality education. It is an understanding of sex education as an area of human potentials that motivates the students to develop essential skills to enable them to self-determine their sexuality and relationships at the various developmental stages and supports them to becoming more empowered in order to live out their sexuality and partnerships in a fulfilling and responsible manner (WHO \& BZgA, 2010). In this way, the students are well nurtured and empowered to deal with present and future sexuality challenges like masturbation.

Today, the holistic pedagogy to sex education is designated in different societies with different but similar names such as prevention education, relationship and sexuality education, family-life education, healthy life style education, comprehensive sex education. United Nations Educational, Scientific and Cultural Organization (UNESCO) prefers the term comprehensive sex education (CSE). Despite the moral defectiveness of CSE, it is interesting to note that a significant body of evidence shows that it enables young people like students of tertiary institutions to develop: accurate and age-appropriate knowledge, attitudes and skills; positive values including respect for human rights, gender equality and diversity, and, attitudes and skills that contribute to safe, healthy, positive relationships (UNESCO, 2018).

\section{Conclusion}

Tertiary institution is a major arena for the acquisition of skills and values to be independent, self-reliant, self-actualized, and relevant to oneself and society. Yet, when students in the university are neither trained on value and character formation nor nurtured in sex education, it becomes difficult for them to handle the challenges of life in whichever form it comes. A well-coordinated sex education by educational leaders is found to be a comprehensive, scientific and supplementary program of reducing the negative effects; mental, sexual, moral, ethical and social challenges of masturbation. Thus, students of tertiary institutions in Nigeria can overcome the challenges of masturbation through adequate value re-orientation, balanced sex education and effective educational leadership. 


\section{Recommendations}

1. Provide guidance to education authorities in our tertiary institutions on how to build support for holistic pedagogy for sex education based on international best practices.

2. Share evidence and researched-based guidance to assist policy-makers, educators and curriculum developers.

3. Review and reassess goals and objectives of tertiary institutions in Nigeria to redirect and sharpen its focus on value and character formation.

4. Strengthen the value orientation of the courses taught and researches carried out in tertiary institutions on sex education to contextualize them into specific and most challenging needs of the students.

5. Review and reform curriculum in tertiary institutions to integrate and accommodate both sex education and value education.

6. Undertake regular and periodic tracer studies on the emotional life of students after their graduation to carry out curriculum adjustments and innovation.

7. Organize conferences, seminars and workshops periodically for school authorities and lecturers on sex education and educational leadership.

8. Promote cooperation and support from parents, families, religious leaders and other community actors, ensuring their support and involvement in holistic sex education of their children.

9. Encourage students to provide inputs on the plan, design, monitoring and evaluation of the sex education programmes.

10. Partner with other ministries (like health ministry), civil society organizations and international non-governmental agencies such as UN.

\section{References}

Aboul-Enein, B. H., Bernstein, J. \& Ross, M. W. (2016). Evidence for masturbation and prostate risk: Do we have a verdict? Journal of the International Society for Sexual Medicine, 4(3), 299-234.

Ayad, B. M., van der Horst, G., \& Du Plessis, S. S. (2018). Revisiting the relationship between the ejaculatory abstinence period and semen characteristics. International Journal of Fertility \& Sterility, 11(4). 238-246.

Catechism of the Catholic Church (CCC). Retrieve on 6/05/2020 from Vatican.va/archive/ccc_css/archive/catechism/p3s2c2a6.htm

Chukwu, L. C., Nnaji, J. N. \& Bua, F. T. (2017). Achieving sustainable development in Enugu State through Values Reorientation and Functional Leadership in Universities. Nigerian Journal of Educational Administration and Planning, 17 (1), 152-177.

Chukwunyere, N. C., Okafor, A. \& Godwins, M. (2017). Managing public secondary schools for value re-orientation amongst students: Economic challenges and prospects in Rivers State Nigerian Journal of Educational Administration and Planning, 17 (1), 152-177.

Coleman, E. (2002). Masturbation as a means of achieving sexual health. Journal of Psychology \& Human Sexuality, 14 (2/3), 5-16.

Evert, J. (2008). If you really loved me. Catholic Answers: San Diego.

Federal Republic of Nigeria (2004). National Policy on Education. Abuja: NERDC

Federal Republic of Nigeria (2013). National Policy on Education. Abuja: NERDC

Gerressu, M., Mercer, C. H., Graham, C. A., Wellings, K. \& Johnson, A. M. (2008). Prevalence of masturbation and associated factors in a British national probability survey. Archives of Sexual Behavaiour, 37, 66-278. 
Higgins, J. A., Trussell, J., Moore, N. B., \& Davidson, J. K. (2010). Young adult sexual health: Current and prior sexual behaviours among non-Hispanic white U.S. college students. Sex Health, 7(1), 34-42.

Ibrahim, A. K., Ehab, A. A., Mahmoud, I. K. \& Amro, A. E (2017). Perception and practices of masturbation by male medical students, Tanta University, Egypt. Egyptian Journal of Community Medicine, 35 (1), 99-109.

Ikwuka, O. I., Igbokwe, I. C., Adigwe, J. E. H. \& Onimisi, R. A. (2019). Assistive technology for effective management of inclusive classroom. International Journal of Educational Research and Development, 7 (1), 128-133.

Kalu, R. E., Jombo-Umeh, N. O. \& Amadi, G. U. (2017). Principals' application of value reorientation in staff personnel administration in secondary schools in Imo State. Nigerian Journal of Educational Administration and Planning, 17 (1), 88-100.

Kaestle, C. E. \& Allen, K. R. (2011). The role of masturbation in health sexual development: Perceptions of young adults. Arch Sex Behav Doi 10.1007/s10508-0109722-0

Khan Chowdhurry, R. H., Khan Chowdhurry, M. R., Nipa, N. S., Kabir, R., Moni, M. A., \& Kordowicz. (2019). Masturbation experience: A case study of undergraduate students in Bangladesh. Journal of Population and Social Studies, 27(4), 359-372.

Robinson, B. B. E., Bockting, W. O., \& Harrell, T. (2003). Masturbation and sexual health: An exploratory study of low income African American women. Journal of Psychology and Human Sexuality, 14 (2-3), 85-102.

Congregation for the Doctrine of Faith (CDF). Persona Humana. Retrieved 6/05/2020 fromhttps://www.vatican.va/roman_curia/congregations/cfaith/documents/rc_con_cf aith_doc_19751229_persona-humana_en.html

Shaibu, L., Odoh F. B. \& Odiba I. A. (2017). Management of secondary education for good leadership quality and sustainable development in Kogi East Education Zone of Kogi State. Nigerian Journal of Educational Administration and Planning, 17 (1), 67-87.

Shekarey, A., Rostami, M. S., Mazdai, K. \& Mohammadi, A. (2011). Masturbation: Prevention \& treatment. Procedia- Social and Behavioral Sciences, 30, 1641-1646. https://doi.org/10.1016/j.sbspro.2011.10.318.

United Nations Educational Scientific and Cultural Organization (UNESCO). (2018). International technical guidance on sexuality education: An evidence-informed approach Education 2030. Paris.

United Nations Population Fund (UNFPA). (2016). Sexuality education - Policy brief No. 1. Federal Centre for Health Education, Cologne.

World Health Organization. (2010). WHO laboratory manual for the examination and processing of human semen ( $5^{\text {th }} \mathrm{ed}$.). Geneva.

World Health Organization (WHO) \& Federal Centre for Health Education (BZgA). (2010). Standards for sexuality education in Europe: A framework for policy makers, education and health authorities and specialists. Cologne, BZgA.

Zimmer, F. \& Imhoff, R. (2020), Abstinence from masturbation and hypersexuality. Arch Sex Behav 49, 1333-1343. https://doi.org/10.1007/s10508-01901623-8 